\title{
An analysis of peer reviewed publications on openness in education in half a century: Trends and patterns in the open hemisphere
}

\author{
Aras Bozkurt \\ Anadolu University \& University of South Africa \\ Suzan Koseoglu \\ University of London \\ Lenandlar Singh \\ University of Guyana
}

\begin{abstract}
Openness in education is an evolving concept which is shaped by the changing needs of societies, cultures, geographies, and economies, thus, it does not have a precise definition. By focusing on four sets of generic keywords - open education, open learning, open educational resources (OERs), and open educational practices (OEPs) - this paper examines research in openness in education through a systematic review of peer reviewed literature. In doing so, the researchers sought to draw attention to existing trends and patterns and possible future trajectories of openness in education. Content analysis, social network analysis, and text-mining are the methods used for data collection and analysis. Findings show that there has been growing interest on openness in education, particularly on OERs, across different fields. Findings also point to OEPs as an emerging area of study, which offers a fertile ground for future research. However, on closer inspection, a divide can be observed between the global north and global south in terms of research output.
\end{abstract}

\section{Introduction}

Openness in education has emerged as a major paradigm for scholarly practice and research in recent years. Although the concept itself is not new in the educational literature from a pedagogical standpoint, digital openness has diverged into many subfields of practice - such as open access, open data, open policies, and open science - and gained significant momentum with open educational resources (OERs) and massive open online courses (MOOCs) (Knox, 2013; Mulder, 2015). Yet, as Rolfe (2017) notes, "the global open education movement is striving toward openness as a feature of academic policy and practice, but evidence shows that these ambitions are far from mainstream" (p. 75). In addition, research on openness in education mostly focuses on OERs or tends to isolate topics that are strongly related to each other. Through a systematic review of scholarly resources, the researchers address this gap in the literature and seek to draw attention to existing trends and patterns and possible future trajectories of openness in education.

According to Weller, Jordan, DeVries, and Rolfe (2018), "openness is not clearly defined and draws upon multiple subject areas, making a well-defined set of literature to include a challenge" (p. 112). In consistent with this argument, Pomerantz and Peek (2016) used the metaphor fifty shades of gray to refer to openness. Similarly, Stewart stated that "openness has many shades of gray" (Bozkurt \& Koseoglu, 2018, para. 3) as the term has multiple dimensions and forms (Smith \& Seward, 2017). Supporting these views, Baker (2017) claims that openness, as an umbrella term, is difficult to define because its nature is flexible and liquid, characterized by "freedom, justice, respect, openness as attitude or culture, the absence of barriers, promotion of sharing, accessibility, transparency, collaboration, agency, self-direction, personalization and ubiquitous ownership" (p. 131-132). Technology, in this respect, is used to enable such visions (Lessig, 2004). Educational technology in particular affects the shift from traditional to online learning (Baker, 2017) as it increases accessibility of open and distance learning (Peter \& Deimann, 2013) and shapes the instructional or learning design (Scanlon, McAndrew, \& O'Shea, 2015). Thus, it can be argued that educational technology is a major component of openness in terms of eliminating barriers in time and space, and has been a catalyst for openness in education (Dalsgaard \& Thestrup, 2015).

This study focused on four generic sets of keywords to explore the literature: open education, open learning, $\mathrm{OER} / \mathrm{s}$, and OEP/s. These specific terms were chosen because they are closely related to openness (McAndrew, 2010; Peter \& Deimann, 2013; Smith \& Seward, 2017). In addition, each of them is a broad 
and interrelated concept encompassing many dimensions of openness. For example, OEP is a multidimensional construct including, but not limited to, OER creation, use and adoption, open scholarship, open pedagogy, and learning (Beetham, Falconer, McGill, \& Littlejohn, 2012; Cronin, 2017; Naidu, 2016). The study of OERs might include educational content as well as open universities, open platforms, systems, and architectures (Koseoglu \& Bozkurt, 2018a; 2018b). Open education and open learning are social and political (Peters \& Britez, 2008) and represent many developments related to the movement of opening up education (Peters, 2008), most of which have been enabled with technology enhanced learning (Brown \& Adler, 2008). In this regard, the study intended to shed light on the following research questions:

1. What are the trends in publications on openness in education in terms of time series, subject area, country distribution, and author affiliation?

2. What patterns can be derived from a lexical and social network analysis of keywords and abstracts?

\section{Background}

Openness in education has multiple roots, and many developments in history affected its evolution. It can be traced back to 1948, when education was accepted a basic human right in the Universal Declaration of Human Rights (http://www.un.org/en/universal-declaration-human-rights/). As can be seen in Figure 1, different but sometimes overlapping forms of openness have emerged throughout history (Jordan \& Weller, 2017). This study explored openness in education as it relates to open education, open learning, OERs, and OEPs, which are described below.

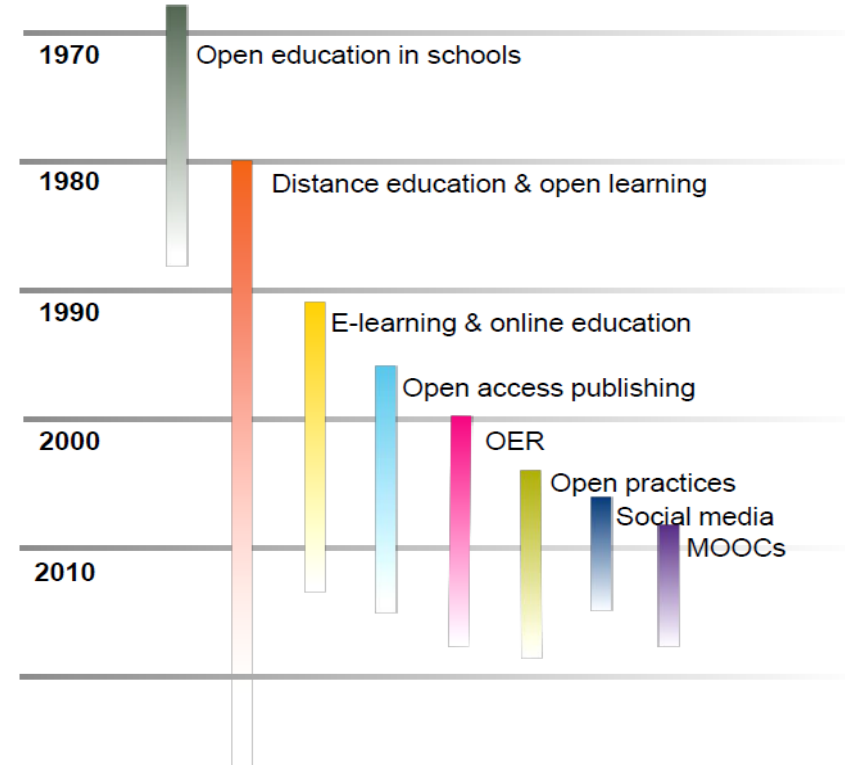

Figure 1. Timeline visualisation of a citation network for openness in education (Jordan \& Weller, 2017, p. 3)

\section{Open education and open learning}

Open education and open learning are overlapping terms, often used interchangeably in the related literature. While open education signifies discipline and area of the study (Jordan \& Weller, 2017), open learning may refer to "the philosophical basis on which open universities are established" (Mishra, 2012, p. 3) as well as open approaches to education, and thus, as Coffey (1988) argued decades ago, it is not "a fixed concept" (p. 195).

Coffey (1977) defined open learning as the removal of both administrative and educational constraints to learning. Also, according to Coffey (1977), an "open learning system is the one in which the restrictions placed on students are under constant review and removed wherever possible" (p. 11). Lewis (1986) identified three characteristics of open learning based on earlier definitions and approaches: (1) "learner- 
centered, rather than institution-centered;" (2) "implies the use of a wide range of teaching/learning strategies;" and (3) concerned with "removing restrictions (barriers) to learning, particularly those barriers inherent in conventional education/training provision" (p. 5). Similarly, according to The Commonwealth of Learning (2000), the educational philosophy of open learning emphasises giving learners choices about medium or media, place of study, pace of study, support mechanisms, and entry and exit points, which are provided mostly with opportunities enabled by educational technologies.

Open education is also commonly used for educational opportunities that allow non-traditional entry points to formal education and more flexible participation patterns through its provision methods (The Commonwealth of Learning, 2000). Thus, on a broader level, open learning and open education refer to similar concepts, as both are concerned with removing administrative and financial (e.g., location, cost of study), educational (e.g., qualifications, prerequisites for learning), personal (e.g., motivation, circumstances), and technological (e.g., limited access to resources) barriers to learning.

\section{Open educational resources (OERs)}

One of the most accepted definitions of OERs is offered by UNESCO and the Commonwealth of Learning (2011): "teaching, learning, and research materials in any medium that reside in the public domain and have been released under an open license that permits access, use, repurposing, reuse, and redistribution by others with no or limited restrictions" (p. v). However, Wiley, Bliss, and McEwen (2014) argued that there is no agreed definition for "open" and "OERs." Research dissemination methods and preferences also add to this confusion. For example, in their bibliometric research on OERs, Zancanaro, Todesco, and Ramos (2015), reported that, ironically, many papers that advocate for openness in education and OERs were published not in open access journals, but in closed ones that provide access when paid.

Barriers in OER creation, use, and adoption are extensively documented in the literature. Atkins, Brown, and Hammond (2007) reviewed the OER movement and examined achievements and challenges, along with new opportunities that came up with OERs. They reported issues with: sustainability, curation and preservation of access, object granularity and format diversity, intellectual property issues, content quality assessment and enhancement, computing and communication infrastructure, scale-up and deepening impact in developing countries. Similarly, Yuan, MacNeill, and Kraan (2008) examined OERs within the context of higher education and reported that policy concerns, curriculum development, financial support, intellectual property, culture of sharing, assessment and accreditation, quality assurance, staff development, student support, technical infrastructure/software, and institutional model were major challenges that higher education faces in terms of OER creation and dissemination. Similar issues and challenges recur in more recent literature on OERs. Bossu, Brown, and Bull (2012) examined a number of OER initiatives in Australia and noted awareness of quality resources and academic culture as existing issues. Murphy (2013) surveyed individuals working in higher education around the world and reported the lack of dedicated resources, cost of redeveloping existing courses and funding in general, and institutional leadership and policy alignment as outstanding challenges. Almendro and Silveira (2018) pointed out that the issue of quality assurance of OERs remains a major challenge. A focus on educational practice has also increasingly been posited as a way to overcome ongoing barriers in OERs (Havemann, 2016).

\section{Open educational practices (OEPs)}

Although there are references to open practices in the 1970's (e.g., Hoy \& Jalovick, 1979), digital OEPs is an emerging field of study that is yet to be matured. In an exploratory review of OEPs, Koseoglu and Bozkurt (2018a) found that most research on OEPs stemmed from studies on OERs, however, a small number of studies explored OEPs in the broader context of networked and open scholarship, open learning and teaching, open systems and architectures, and open source software. The strong connection between OERs and OEPs is not surprising, as OEPs emerged from the study of OER, and are often discussed in the literature in the context of removing barriers to OER creation, use and adoption. Ehlers and Conole (2010) noted that a focus on OEP is much needed to fully benefit from OER and unleash its actual potential. Ehlers (2011) further suggested that the shift from access to, and availability of, open content to open practice was much needed for "improving learning quality through OER" (p. 2) and to "promote openness of learning architectures and transforming learning scenarios" (p. 8). This shift in focus from resource to practice is also evident in The Cape Town Open Education Declaration (2007a), which states: 
[O]pen education is not limited to just open educational resources. It also draws upon open technologies that facilitate collaborative, flexible learning and the open sharing of teaching practices that empower educators to benefit from the best ideas of their colleagues. It may also grow to include new approaches to assessment, accreditation and collaborative learning. (para. 4)

Thus, OEPs should best be understood as "collaborative practices that include the creation, use, and reuse of OER, as well as pedagogical practices employing participatory technologies and social networks for interaction, peer-learning, knowledge creation, and empowerment of learners" (Cronin, 2017, p. 18). Perhaps because of the fresh emphasis on collaboration and social learning, recent research on OEPs reveals previously ignored or understudied factors that affect engagement with open resources and open teaching and learning practices, such as learning in communities and in collaboration with others (both face-to-face and networked), and authentic learning in groups (Laverde \& Arias, 2015; Nerantzi \& Gossman, 2015; Stylianakis, Moumoutzis, Arapi, Mylonakis, \& Christodoulakis, 2014).

\section{Method}

\section{Research method and design}

This research used a systematic review to identify trends and patterns in peer-reviewed literature on openness in education. Because systematic reviews synthesise a sheer volume of research (Gough, Oliver, $\&$ Thomas, 2012), they are especially effective to provide a summary of the literature, identify the current state of the art, and guide researchers in future work (Petticrew \& Roberts, 2008). As part of the systematic review, the researchers used content analysis (Banks, Louie, \& Einerson, 2000) to address the first research question, and text-mining (Hearst, 2003) and social network analysis (SNA) (Hansen, Shneiderman, \& Smith, 2010) to address the second research question. Content analysis (through bibliographic data indexed in the Scopus database) was used to identify research trends (e.g., time series, subject area, country distribution, and institutional affiliation). More specifically, SNA and lexical analysis were used to identify research patterns. SNA was used to analyse and then visualise keyword patterns in sampled publications, while lexical analysis was used to identify semantic relationships within textual data (titles and abstracts of the sampled publications). These different analytical approaches for data collection and analysis helped the researchers to triangulate research findings (Denzin, 1970; Kimchi, Polivka, \& Stevenson, 1991). Derived from the idea of multiple operationism (Campbell \& Fiske, 1959), triangulation is used to increase validation (Denzin, 1970) and the robustness of research findings (López, Valenzuela, Nussbaum, \& Tsai, 2015).

\section{Sampling}

The publications that were included in the research corpus were obtained by using the stated sets of keywords: open education, open learning, OEP/s, and OER/s. Scopus, one of the largest databases of peerreviewed literature (Scopus, n.d.), was used. Before conducting a search in Scopus, researchers also checked other databases such as ERIC and Web of Science; however, Scopus provided the most comprehensive results. The inclusion criteria for the sampling was: (1) the resource was indexed in Scopus; (2) the resource was written in English or had an abstract in English, and (3) the resource had at least one of the searched keywords in its title. In order to obtain a holistic view, no time ranges were specified in the search. In the screening process, a total of 1006 studies were identified. After filtering studies/papers that were irrelevant to the purposes of this study (e.g., editorials, notes, etc.), the researchers continued their analysis with a total of 970 publications that met the inclusion criteria.

\section{Data collection and analysis}

This research benefited from content analysis, social network analysis, and text-mining. The overall data collection and analysis process is shown in Figure 2. In the first phase, the researchers conducted content analysis on 970 publications identified as sources of data. Content analysis can use qualitative, quantitative, or both methodological approaches (Banks, Louie, \& Einerson, 2000) to reach valid and replicable research findings (Krippendorff, 1980). These publications were analysed using the bibliographic data indexed in the Scopus database (i.e., time series, subject area, country distribution, and institutional affiliations). 
In the second phase, the research was carried out using SNA which is a technique to study, track, and compare the dynamics of networks and their components (Hansen et al., 2010). In SNA, a network is usually visualised as a social network diagram, where nodes are represented as points and edges are represented as lines. In this research, keywords were identified as nodes and their relationships based on co-occurrence were identified as ties. Following that, keywords were visualised in a grid layout by referencing their betweenness centrality and listed according to their degree. By doing so, the researchers were able to identify the keywords that hold significant positions in the network and the relationships among them based on their tie weights.

In the third and final process, the researchers used text-mining. Text-mining transforms lexically cooccurring information from natural language into semantic patterns (Hearst, 2003; Smith \& Humphreys, 2006). In this phase, the study sample was examined through text-mining and emerging themes and concepts were visualised and discussed.

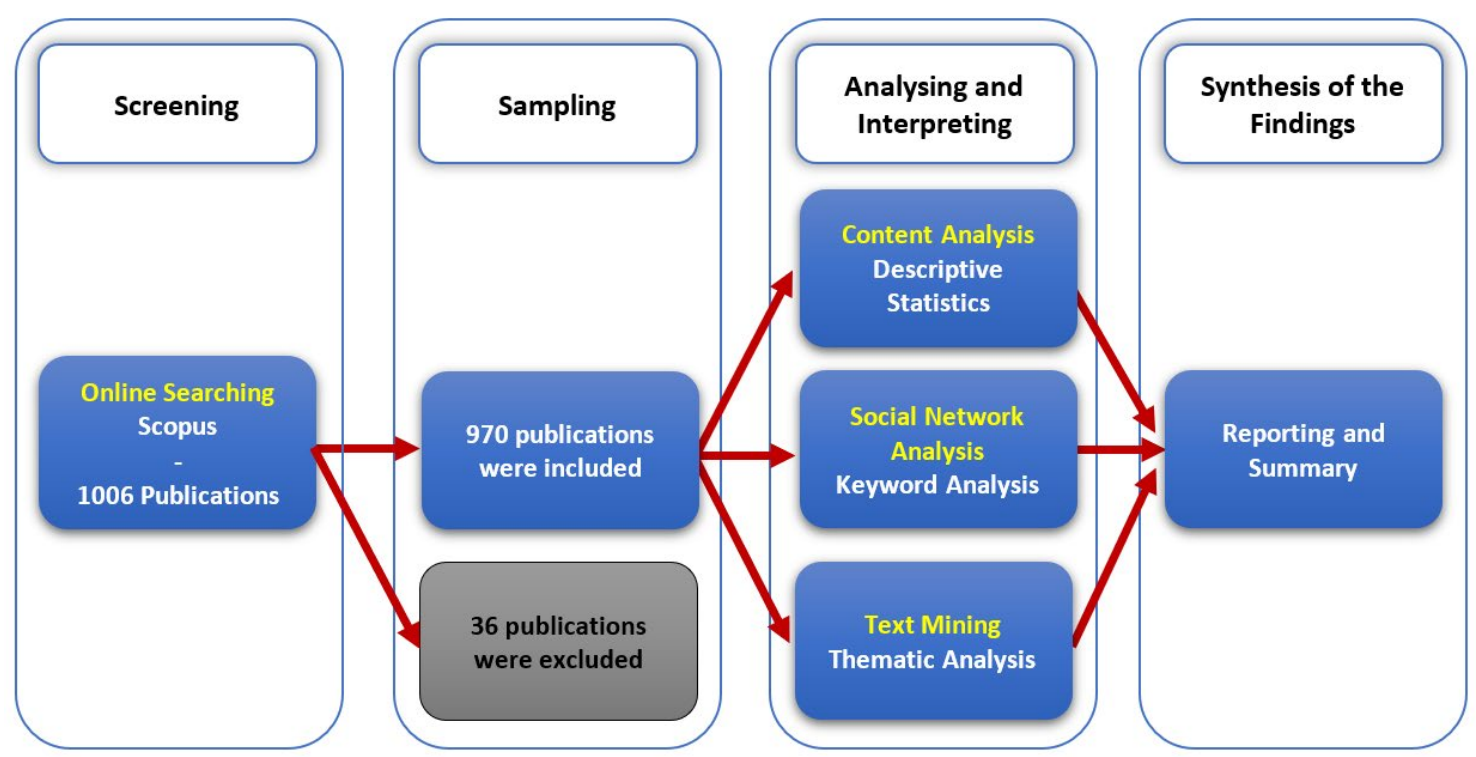

Figure 2. The overall data collection and analysis process

\section{Strengths and limitations}

This research examined the literature from multiple perspectives using innovative techniques such as social network analysis and text-mining in addition to conventional techniques such as content analysis. However, some limitations should be noted. First, Scopus indexes peer reviewed publications that are either written in English (full-text) or that are written in other languages but with English abstracts and titles, which limits the study sample. There might be many other publications on the topic with full-texts and/or abstracts written in other languages and these works may provide important research findings, yet sampling these publications would have been beyond the researchers' abilities. Thus, it is important to note findings in this paper reveal partial trends and pattern on openness in education. Furthermore, the researchers acknowledge that there are many valuable publications in the grey literature, such as reports or white papers, which are not included in the study sample. Second, publications with the selected keywords in their titles were included to the research corpus with the assumption that these publications would serve the purposes of the research well because of their focal points. This approach also helped the researchers narrow down the scope of their research. However, the researchers also acknowledge that in doing so, some other areas of research related to openness in education are likely omitted, and the research provides a partial and constructed view of openness in education. 


\section{Findings and discussion}

\section{Trends}

Time series

The time series graph (Figure 3) shows that in total, from 1969 to 2017, the publications spanned over 48 years. When each trend was examined separately, we observed that although there were fluctuations, there was a trend toward increasing numbers of publications in all areas in the last decade or so, especially after 2009. We also observed that open learning and open education were presented within a similar range in the graph. This was not surprising considering that the terms can be used to refer to similar concepts. The literature mainly covered topics related to open learning and open education from 1969 to 2005, however by 2006 and 2007, topics related to OERs and OEPs started appearing. The most visible increase in the number of publications was in publications on OER, whereas OEP publications appeared to increase on a much slower and less frequent rate. These findings align with Jordan and Weller (2017) who depicted a similar trend in open education in schools, distance education and open learning, open educational resources, and open practices (Figure 1).

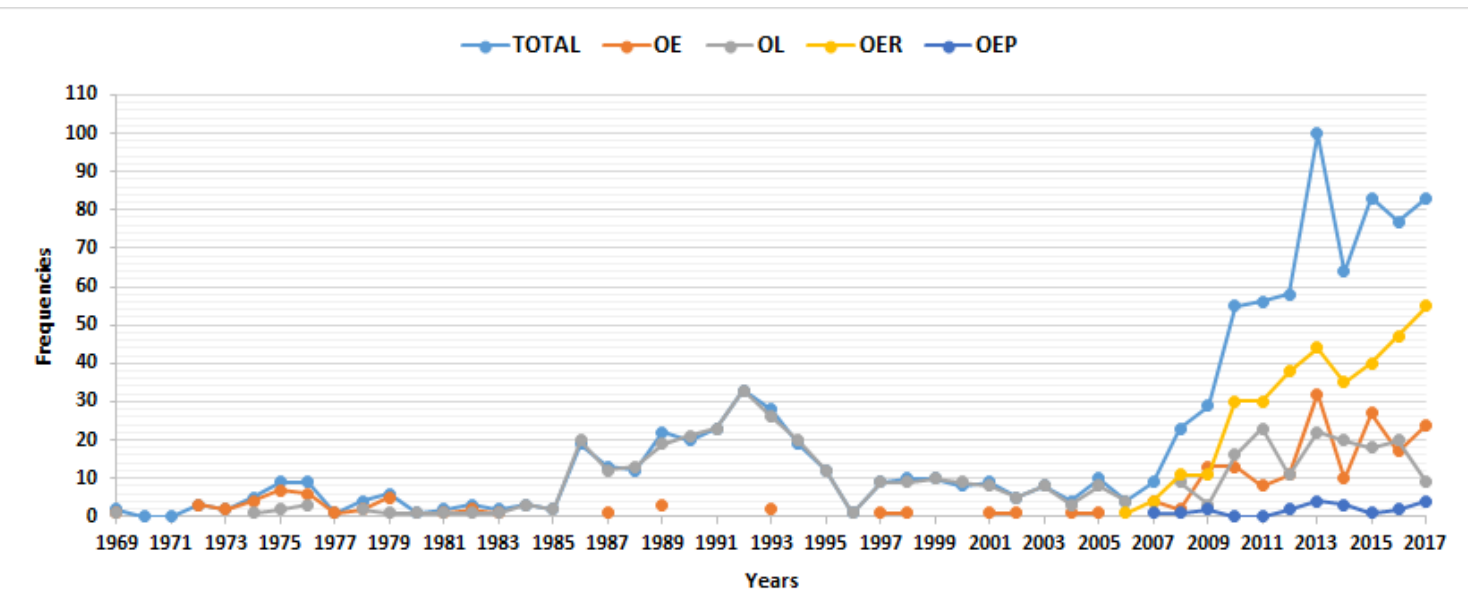

Figure 3. The time series of sampled publications related to open learning (OL), open education (OE), OEPs, and OERs. Note: One study may have included more than one keyword that was identified as an inclusion criterion for the study.

The first appearance of research on openness in education in 1969 is not a coincidence. In their seminal work, "Distance education: A Systems View," Moore and Kearsley (2005) identify 1960s as the start of a third generation of distance education, which was labelled open universities. However, caution is needed here as open education is also used to describe student centred and progressive approaches to education in the 1960s and 1970s, and does not necessarily imply digital or distance learning.

Some important developments, such as the emergence of cMOOCs in 2008 and xMOOCs in 2011 (Siemens, 2013), OERs (UNESCO, 2002), and OEPs (Geser, 2007), might explain the sudden increase in the number of publications on openness around 2007. It is also possible that the increasing interest was as a result of collective efforts in openness-oriented initiatives, such as the first World OER Congress in 2012 (https://www.oercongress.org/congress/world-oer-congress-2012/). Similar trends were reported in three meta studies. For instance, Bozkurt et al. (2015) examined research trends in distance education between 2009 and 2013 and found that there was a paradigm change from distance education to open and distance learning, and OER was the most preferred keyword among the 861 articles they explored. In other research, which examined publications in the Journal of Distance Education, Zawacki-Richter and Naidu (2016) reported that the years between 2010 and 2014 marked the emergence of interactive learning, MOOCs and OERs (which is consistent with this study's findings on trends in OER and to some extent trends in open education. A similar trend was also noted by Zawacki-Richter, Alturki, and Aldraiweesh (2017), who examined the articles published in the Journal of International Review of Research in Open and Distributed Learning (IRRODL) and identified the years between 2011 and 2015 as the emergence of MOOCs and OERs, which might explain the peak that was observed in 2013 in the sampled publications (Figure 3). 
Even though the studies above indicate an increasing interest in OERs, MOOCs and other opennessoriented initiatives, it is also noteworthy that the interest derives mostly from the field of distance education than conventional face-to-face education.

\section{Subject area}

The subject areas of published papers demonstrated that social sciences published the most research on the search terms (44.51\%) (Table 1). This was not surprising as Scopus, the database researchers used in this study for sampling, classifies education under social sciences. Computer science (23.07\%) and engineering $(8.51 \%)$ are other subject areas that engage in research on openness in education. When social sciences (44.51\%) was excluded from the list, we saw that the publications were covered by a variety of subject areas from different disciplines of study (55.49\%). This might indicate that the topics explored in this study are not confined to the field of education; rather, they are largely adopted by other subject areas and fields. Though there was a dominance of social sciences and computer science in the number of publications, the findings suggest that the literature is becoming more interdisciplinary than in the past. This is important because interdisciplinary research refers to studies carried out by researchers from different disciplines (Aboelela et al., 2007), and such research can provide innovative perspectives to any field (Nissani, 1997; Veletsianos \& Shepherdson, 2015).

Table 1

The distribution of the subject areas of the sampled publications

\begin{tabular}{|c|c|c|}
\hline Subject Area & Frequency & Percentage \\
\hline Social Sciences & 633 & 44.51 \\
\hline Computer Science & 328 & 23.07 \\
\hline Engineering & 121 & 8.51 \\
\hline Medicine & 83 & 5.84 \\
\hline Mathematics & 54 & 3.80 \\
\hline Business Management and Accounting & 51 & 3.59 \\
\hline Arts and Humanities & 35 & 2.46 \\
\hline Psychology & 29 & 2.04 \\
\hline Decision Sciences & 21 & 1.48 \\
\hline Nursing & 13 & 0.91 \\
\hline Economics Econometrics and Finance & 6 & 0.42 \\
\hline Environmental Science & 6 & 0.42 \\
\hline Earth and Planetary Sciences & 5 & 0.35 \\
\hline Agricultural and Biological Sciences & 4 & 0.28 \\
\hline Biochemistry Genetics and Molecular Biology & 4 & 0.28 \\
\hline Energy & 4 & 0.28 \\
\hline Chemistry & 3 & 0.21 \\
\hline Health Professions & 3 & 0.21 \\
\hline Physics and Astronomy & 3 & 0.21 \\
\hline Chemical Engineering & 2 & 0.14 \\
\hline Multidisciplinary & 2 & 0.14 \\
\hline Undefined & 12 & 0.84 \\
\hline
\end{tabular}

* One publication can be classified in more than one subject area

Country distribution and institutional affiliation

The geographic distribution of the papers according to author affiliations showed intriguing findings (Figure 4). First, in general, the publications originated from countries where open learning or distance education is a part of the mainstream education. For instance, UK $(n=210,21.6 \%)$, United States $(n=129$, $13.2 \%)$, Spain $(n=79,8.1 \%)$, Australia $(n=47,4.8 \%)$, China $(n=47,4.8 \%)$, Germany, $(n=39,4.0 \%)$, Canada $(n=34,3.5 \%)$, Netherlands $(n=27,2.8 \%)$, and Turkey $(n=21 ; 2.2 \%)$ (Table 2$)$. 
Table 2

The distribution of institutional affiliations within the sampled publications

\begin{tabular}{|l|l|l|r|}
\hline Affiliation & Country & Frequency & Percentage \\
\hline Open University of UK & United Kingdom & 67 & 6.91 \\
\hline The Technical University of Madrid & Spain & 22 & 2.27 \\
\hline Universidad Tecnica Particular de Loja & Ecuador & 19 & 1.96 \\
\hline Open University of the Netherlands & Netherlands & 18 & 1.86 \\
\hline KU Leuven & Belgium & 14 & 1.44 \\
\hline Athabasca University & Canada & 13 & 1.34 \\
\hline Anadolu University & Turkey & 11 & 1.13 \\
\hline The National University of Distance Education & Spain & 11 & 1.13 \\
\hline University of Cape Town & South Africa & 11 & 1.13 \\
\hline Tecnologico de Monterrey & Mexico & 10 & 1.03 \\
\hline Others & & 774 & 79.79 \\
\hline
\end{tabular}

The institutional affiliation of authors provided interesting results (Table 2). Data also showed that the leading contributors to the literature were from universities known for their open or distance education programs and initiatives. For instance, the Open University of UK (the leading institution on the list with 67 publications) was one of the first universities to introduce open education. Athabasca University is known for its successful online learning programs and Anadolu University is known for its massive number of students: more than 3 million. However, it should also be noted that some prominent higher education institutions that adopted open learning or distance education did not appear on the list, This might indicate that not all institutions which embrace openness in education publish research on the topic. It is also interesting to note how individual efforts can influence geographical statistics. For example, a single researcher from Ecuador published 15 publications which raised the country's research profile on the subject.

Country distribution of the sampled publications showed, based on the developing and developed country classification by Nielsen (2011), the rate of research output to be higher in developed countries compared to developing countries. In addition, the country distribution of sampled publications (Figure 4) and the distribution of countries' Gross National Income (GNI) (Appendix A) were strikingly similar.
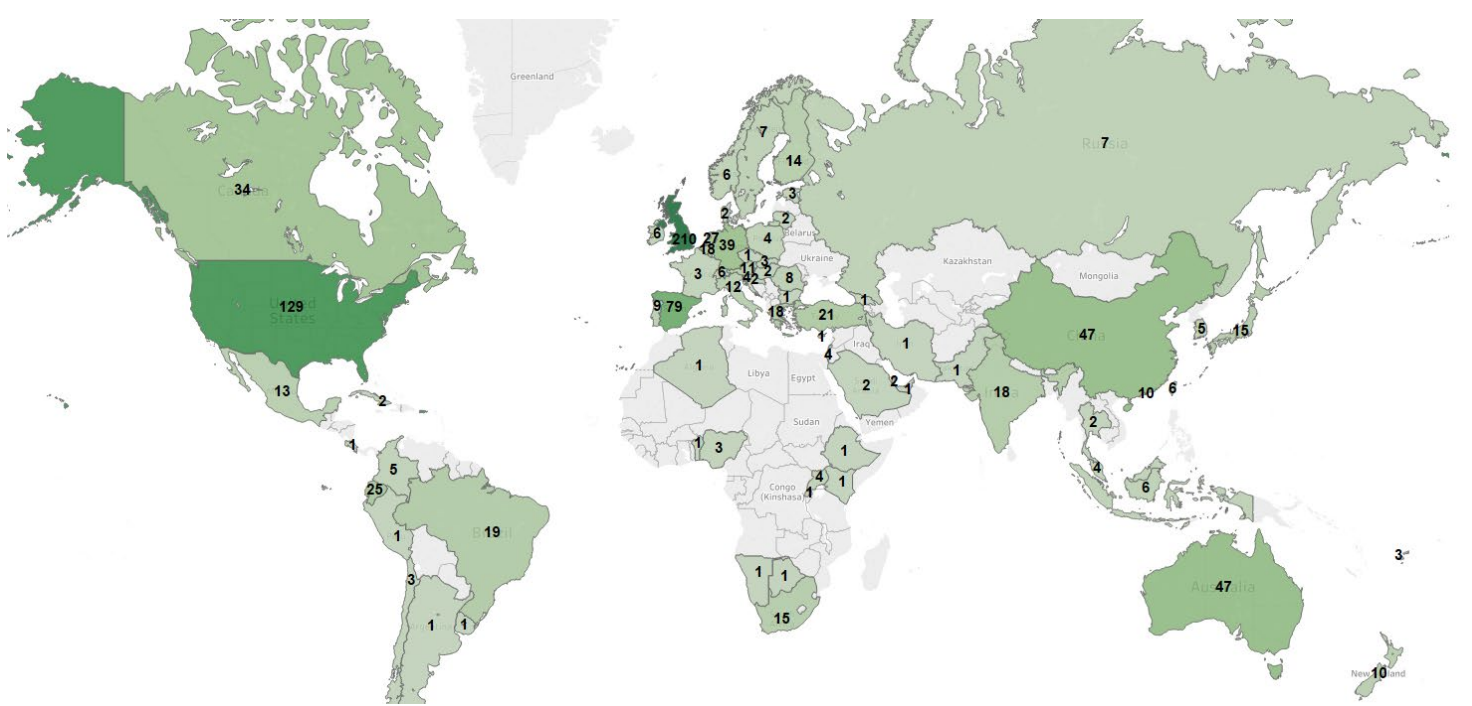

Figure 4. The country distribution of the sampled publications according to author affiliations

Trends in country distribution were quite similar to those reported by Zancanaro et al. (2015), who researched OERs and reported that the majority of publications on OERs were "from North America (specifically from the United States of America and Canada) and Europe (specifically, from the United Kingdom, Spain, Netherlands and Germany)" (p. 11). Thus, the current portrait of country distribution raises important questions to address. Can openness in education serve as a mean to democratise education in developing countries, as many researchers have suggested (e.g., Thille, 2008; Vest, 2006), when the research is predominantly conducted elsewhere? Is The battle for the open: How openness won and why it 
doesn't feel like victory (Weller, 2014) - the shift in perspective from a focus on what is open, to how and why it is open - limited to developed countries? Indeed, Weller et al. (2018) and also Bateman, Lane, and Moon (2012) highlighted that the interest in OERs from the global north (e.g., North America) was higher compared to global south (e.g., Sub-Saharan Africa). Kanwar, Balasubramanian, and Umar (2010) also reported that "the flow of OER is happening in one direction only, from the Global North to the Global South" (p. 68). Moreover, Wiley et al. (2014) pointed out that localisation, the adaptation of open resources in different cultural contexts, is a major challenge in OER use and adoption, and argued for a need to pay attention to "religious, cultural, and other local knowledge necessary to customize open educational resources for optimal use" and "building local capacity" (Wiley et al., 2014, p. 786).

These issues require further exploration because openness in education may not be effective to lessen the digital divide, which is described as "the disparity that exists among individuals and communities around the world with varying degrees of access to digitally-mediated information and communication technologies (ICTs) and their ability to benefit from digital resources" (Pazurek and Feyissa, 2015, p. 204). As Poynder (2018) argued there may, in fact, be an open divide.

\section{Patterns}

Keyword network analysis

For this analysis, out of all keywords $(n=1446)$, the ones equal to or more than 2 occurrences $(n=250)$ were selected and then imported to NodeXL, a social network analysis software. Keywords were laid out using the grid layout algorithm and grouped by cluster using the Clauset-Newman-Moore cluster algorithm. Keyword layout order was defined by betweenness centrality (BC), which, in this research context, is a value that indicates a keyword's ability to bridge different keywords in a network (Figure 5).

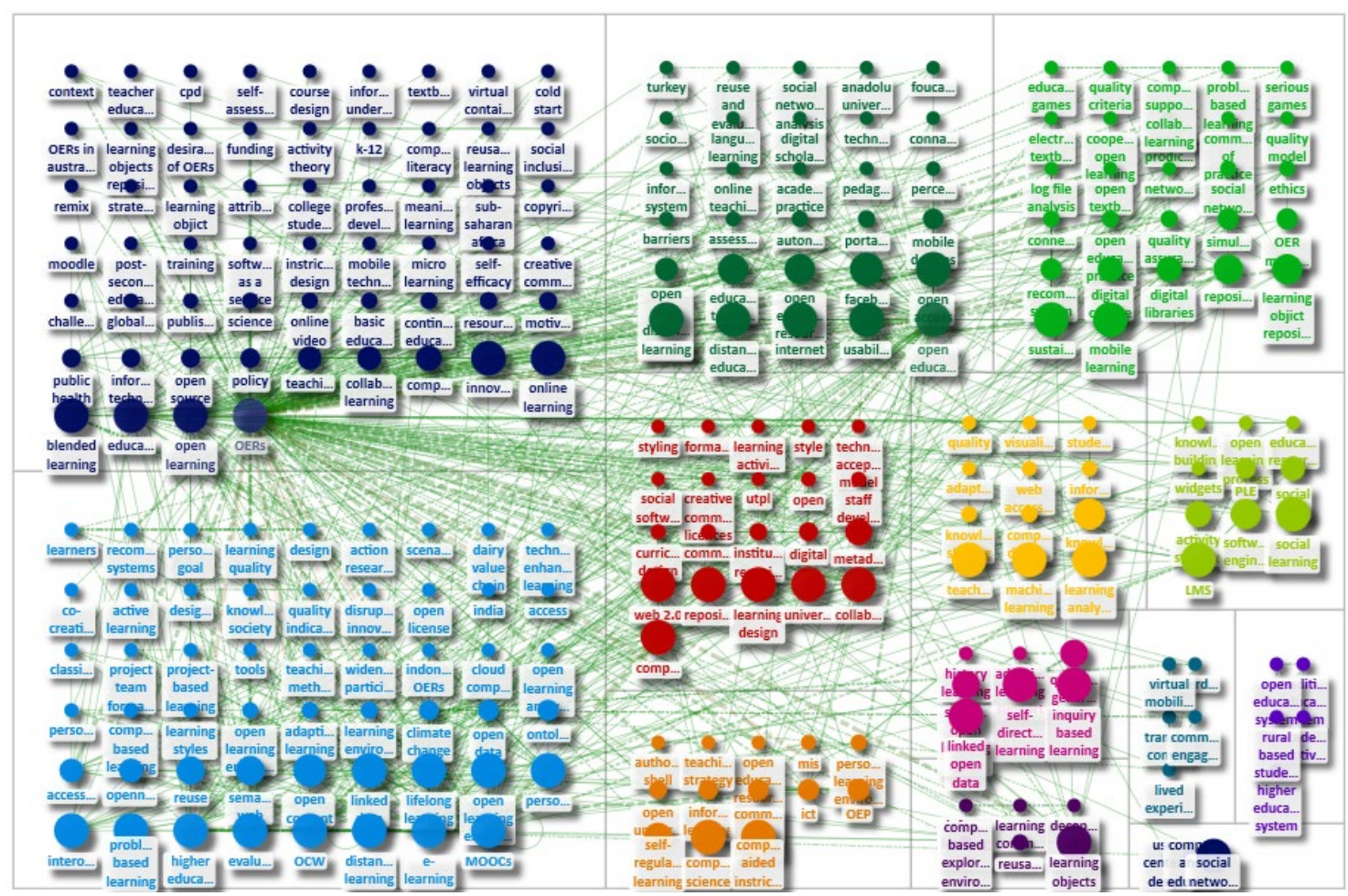

Figure 5. The sociogram based on a social network analysis of the keywords in the sampled publications

The analysis revealed 1028 ties among the 250 keywords (see Appendix B for a larger version of the sociogram). OERs (BC:19321.0), open education (BC: 3101.7), open learning (BC: 2140.6), MOOCs (BC: 1834.7), and e-learning (BC:1253.8) were the top five central keywords according to betweenness centrality and degree centrality metrics (see Table 3 for the top 30 keywords ranked according to their betweenness centrality and degree centrality). 
Table 3

The betweenness centrality metrics of the sampled keywords

\begin{tabular}{|c|c|c|c|c|c|c|c|}
\hline \multicolumn{4}{|c|}{ Keywords ranked according to betwenness centrality } & \multicolumn{4}{|c|}{ Keywords ranked according to degree centrality } \\
\hline \# & Keyword & Degree & Betweenness Centralit & $\#$ & Keyword & \begin{tabular}{|l|l} 
Degree & \\
\end{tabular} & Betweenness Centrality \\
\hline 1 & OERs & 177 & 19321.0 & 1 & OERs & 177 & 19321.0 \\
\hline 2 & open education & 76 & 3101.7 & 2 & open education & 76 & 3101.7 \\
\hline 3 & open learning & 51 & 2140.6 & 3 & open learning & 51 & 2140.6 \\
\hline 4 & MOOCs & 42 & 1834.7 & 4 & e-learning & 43 & 1253.8 \\
\hline 5 & e-learning & 43 & 1253.8 & 5 & MOOCs & 42 & 1834.7 \\
\hline 6 & education & 40 & 1135.2 & 6 & education & 40 & 1135.2 \\
\hline 7 & linked open data & 5 & 1059.0 & 7 & OCW & 34 & 347.6 \\
\hline 8 & component & 13 & 732.8 & 8 & higher education & 29 & 312.1 \\
\hline 9 & learning objects & 19 & 573.8 & 9 & collaboration & 27 & 403.9 \\
\hline 10 & learning analytics & 11 & 516.0 & 10 & university & 24 & 250.0 \\
\hline 11 & computer aided instrict & 5 & 484.0 & 11 & evaluation & 21 & 336.9 \\
\hline 12 & blended learning & 16 & 482.1 & 12 & learning objects & 19 & 573.8 \\
\hline 13 & distance learning & 11 & 412.2 & 13 & distance education & 19 & 123.5 \\
\hline 14 & collaboration & 27 & 403.9 & 14 & learning & 19 & 106.8 \\
\hline 15 & OCW & 34 & 347.6 & 15 & sustainability & 18 & 205.3 \\
\hline 16 & evaluation & 21 & 336.9 & 16 & web 2.0 & 18 & 102.4 \\
\hline 17 & higher education & 29 & 312.1 & 17 & personalization & 17 & 163.4 \\
\hline 18 & problem-based learning & 5 & 306.7 & 18 & linked data & 17 & 84.7 \\
\hline 19 & inquiry based learning & 6 & 290.8 & 19 & blended learning & 16 & 482.1 \\
\hline 20 & mobile learning & 11 & 279.6 & 20 & LMS & 16 & 248.2 \\
\hline 21 & university & 24 & 250.0 & 21 & innovation & 16 & 95.6 \\
\hline 22 & LMS & 16 & 248.2 & 22 & open access & 16 & 90.8 \\
\hline 23 & usability & 10 & 234.0 & 23 & repositories & 16 & 55.8 \\
\hline 24 & learning design & 6 & 215.7 & 24 & online learning & 15 & 210.3 \\
\hline 25 & interoperability & 14 & 210.8 & 25 & semantic web & 15 & 53.2 \\
\hline 26 & online learning & 15 & 210.3 & 26 & interoperability & 14 & 210.8 \\
\hline 27 & repository & 13 & 207.4 & 27 & teachers & 14 & 169.9 \\
\hline 28 & sustainability & 18 & 205.3 & 28 & reuse & 14 & 50.3 \\
\hline 29 & machine learning & 4 & 203.7 & 29 & competences & 14 & 41.4 \\
\hline 30 & social learning & 4 & 200.7 & 30 & OEP & 14 & 27.1 \\
\hline$n+$ & Others & 1290 & 3871.5 & $n+$ & Others & 1290 & 3871.5 \\
\hline
\end{tabular}

The study also analysed the strength of relationships among the keywords. To do this, ties among keywords were ranked according to their tie weights (TW) (Table 4). The analysis revealed that the OERs-OERs tie (TW: 120) was a self-loop: a significant amount of research on OERs was isolated from other areas of research. On the other hand, the analysis also showed the broad range of ties OER research had with other areas of study, such as open education (TW: 120), e-learning (TW: 115), OpenCourseWare (TW: 112), and to a lesser extent with MOOCs (TW: 84) and OEPs (TW: 48). The analysis also showed that OERs were mostly concerned with higher education (TW: 63). Interestingly, the tenth highest relationship TW was MOOCs and open education (TW: 27), which was the only relationship where OER was not on any side of the equation.

The SNA findings were significant from multiple aspects. First, as the time series graph shows, OER was the most popular and the fastest growing area of study. Yet SNA analysis suggested that research on OERs is mostly focused on OERs itself. It was, however, promising to see connections with other emerging areas of study such as OEP, which is heavily concerned with removing barriers to OER use and adoption, as we explained in the section Background. Second, MOOCs seem to be one of the primary drives to engage in research on openness in education. Thus, findings, to a certain extent, confirmed the view that "Open Educational Resources (OERs) and Massive Open Online Courses (MOOCs) have surfaced at the forefront" of openness in education (Knox, 2013, p. 21). The focus on higher education should also be noted, as a disproportionate interest in higher education may limit the scope and capacity of open education initiatives. 
Table 4

The tie weights of the sampled keywords

\begin{tabular}{|c|c|c|}
\hline Keyword 1 & Keyword 2 & Tie Weight \\
\hline OERs & OERs & 120 \\
\hline open education & OERs & 120 \\
\hline e-learning & OERs & 115 \\
\hline OCW & OERs & 112 \\
\hline MOOCs & OERs & 84 \\
\hline higher education & OERs & 63 \\
\hline OEP & OERs & 48 \\
\hline linked data & OERs & 40 \\
\hline OERs & repositories & 27 \\
\hline MOOCs & open education & 27 \\
\hline collaboration & OERs & 24 \\
\hline learning objects & OERs & 24 \\
\hline education & OERs & 22 \\
\hline competences & OERs & 20 \\
\hline OERs & innovation & 20 \\
\hline OERs & policy & 18 \\
\hline connexions & OERs & 18 \\
\hline OERs & open learning & 15 \\
\hline metadata & OERs & 14 \\
\hline OERs & reuse & 14 \\
\hline OERs & sustainability & 12 \\
\hline OERs & informal learning & 12 \\
\hline lifelong learning & OERs & 12 \\
\hline OERs & repository & 12 \\
\hline OERs & reusable learning objects & 12 \\
\hline accessibility & OERs & 10 \\
\hline
\end{tabular}

Weller et al. (2018) analysed citation networks in 172 papers focusing on openness in education and found that OERs, open practices, MOOCs, open access publishing, distance education and open learning, open education in schools, e-learning and online education, and social media were the major themes. Findings from SNA were in line with Weller et al. (2018) in terms of keyword analysis and overlapping themes and nodes. MOOCs emerged as a significant keyword in the analysis, which was consistent with the studies discussed in the section Time Series (i.e., Zawacki-Richter et al., 2017; Zawacki-Richter \& Naidu, 2016). In addition, the fact that e-learning and open learning were two significant nodes in the keyword network further strengthens the argument by Bozkurt et al. (2015) that there has been a paradigm shift from distance education to open learning and e-learning. These findings further demonstrate how ICT has shaped openness with the opportunities they provide (e.g., learning anytime anywhere with the help of e-learning).

Lexical analysis

In this section, the results of the text-mining analysis are presented along three connected pathways that emerged from the sampled publications and that are relevant to the research questions posed. 


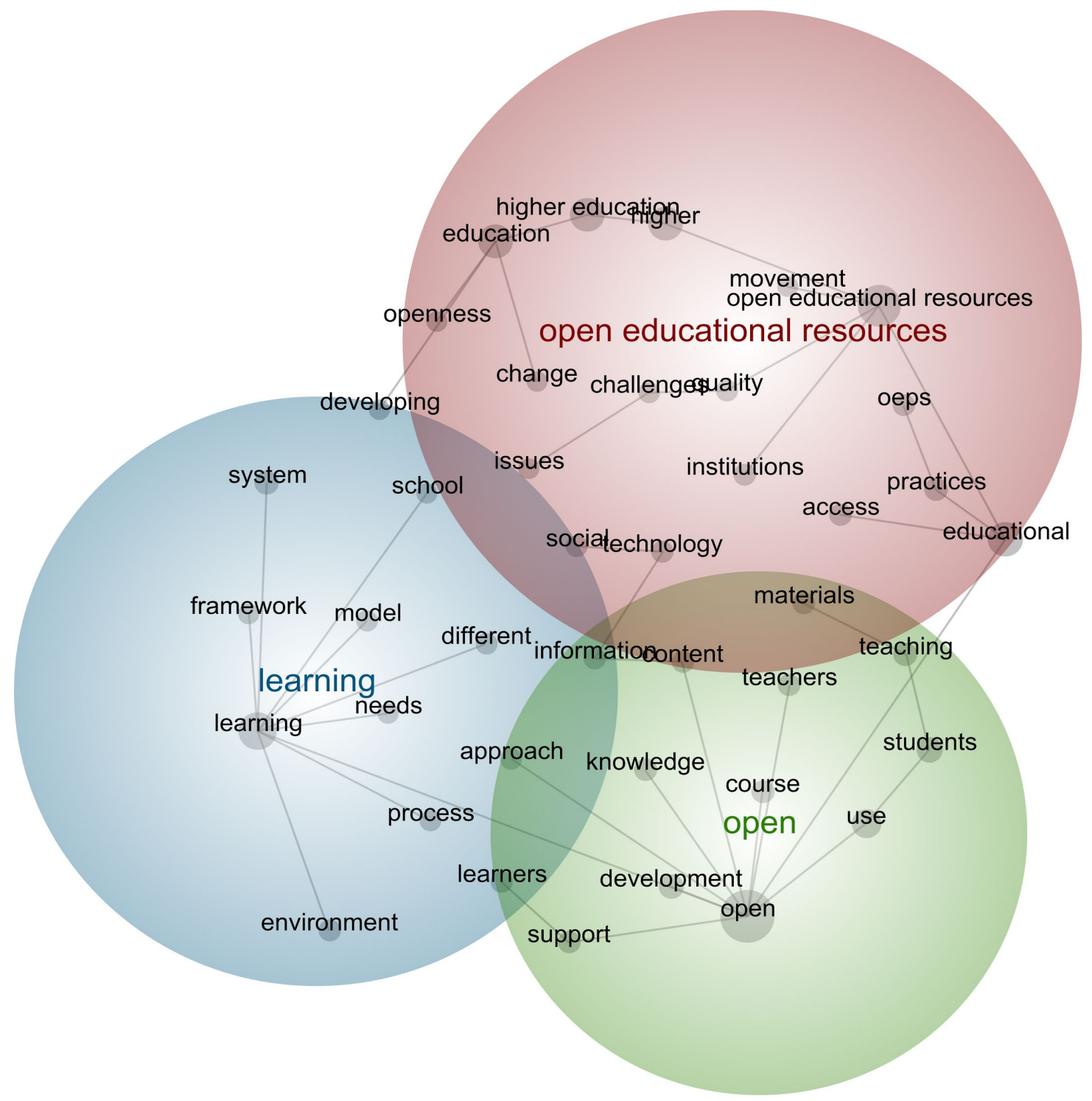

Figure 6. Thematic concept map based on a lexical analysis of the titles and abstracts of sampled publications

1. Barriers in OERs (see the path from open educational resources into quality, challenges and issues in the theme "open educational resources"): The first pathway which emerged in lexical analysis is also widely discussed in the related literature, as noted in the Background section of this paper. Even though there are many advantages of using OERs (McGreal, 2017), the adoption of OERs in educational contexts is lower than expected (Ehlers et al., 2011). As the lexical analysis showed, lack of quality is one of the most pressing issues to overcome (also see Camilleri, Ehlers, \& Pawlowski, 2014; Wiley et al., 2014). As noted in the section Background and also in the discussions above in Findings, sustainability, localisation, business models, discovery problems, intellectual property, appropriate and culturally relevant pedagogies are some other issues that need to be addressed (Wiley et al., 2014).

2. OERs as vision for higher education (see the cluster that shows paths from open educational resources into movement and higher education - the latter then diverges into openness and change - in the theme "open educational resources"): This pathway aligns with the discussions in the literature where the openness movement (also known as opening up education) is often posited as a change agent for higher education (Lane, 2011). The movement supports the view that "ICT and OER in education will increase both efficiency and fairness of education" (Sabadie, Muñoz, Punie, Redecker, \& Vuorikari, 2014, p. 8) and has gained momentum in the 2000s, which might explain 
the increase in the sampled publications within the same period (Figure 3). It was interesting to see the close connection to higher education, which was also something we observed in the SNA and in the relevant literature on OERs (e.g., Murphy, 2013; Yuan et al., 2008).

3. Relationship between OER and OEPs (see the path from open educational resources into educational, practices, and OEPS in the theme "open educational resources"): This pathway covers a recent, yet important issue because while OERs are on the agenda of higher education and other critical stakeholders, their use in higher education has not yet "reached a critical threshold" (Ehlers \& Conole, 2010, p.1). Progress in the open sphere continues from the first phase, which is about access to and availability of OERs, to the second phase, which in turn is about improving quality, ensuring actual use (Andrade et al., 2011; Camilleri et al., 2014) and "improving learning experiences and innovate educational scenarios" through OEPs (Ehlers, 2011, p. 3). This progress is increasingly viewed as a necessity because of the fact that "the current focus in OER is mainly placed on building more access to digital content. There is little consideration of whether this will support educational practices, promote quality and innovation in teaching and learning" (Andrade et al., 2011, p.11). Thus, this theme is strongly related to the first theme we discussed in this section, Barriers in OERs.

\section{Conclusion and implications}

We conducted a systematic analysis of peer reviewed publications on openness in education, explored through four sets of keywords: open learning, open education, OEPs, and OERs. Key patterns and trends on the topic were identified through a triangulation of content analysis, social network analysis and textmining techniques. The review covered publications from 1969 to 2017, almost half a century of research. As a subject area, social sciences, which includes education as a sub-field in this study, dominated research on openness in education. Publications started to increase in number and diversify by 2006-2007, which resulted in a rich body of literature across different disciplines. Findings suggest that openness in education has increasingly become an interdisciplinary research topic.

OERs, open education, open learning, MOOCs, and e-learning were identified as the most central keywords in the complex ecology of openness. The analysis of keyword relationships showed that, despite its relatively short history, research on OERs dominates the field, either in connection with other areas such as MOOCs or OpenCourseWare, or to a greater extent, in isolation from other areas of study in its ecology. Three prominent themes in the literature were identified through a lexical analysis of paper titles and abstracts: (1) barriers in OERs, (2) OERs as vision for higher education, and finally, (3) the relationship between OER and OEPs. Findings indicated that there are still critical issues that need to be resolved in the field of OERs despite the promising narratives of equity and access. We can anticipate seeing more research on OEPs and OERs, and OEPs alone, considering the growing interest on open processes and practices, particularly in terms of addressing barriers in OER creation, use, and adoption. However, findings also showed that OEP research is still under-explored. This offers a fertile ground for future research.

Most strikingly, country distribution of publications revealed that research on the topic mostly stemmed from developed countries. This finding raises questions as to the sustainability of openness in education and its efficiency and effectiveness to lessen the digital divide. Given that bridging the digital divide is a major concern in openness in education, we find, although partial, the trends and patterns identified in this study in terms of limited research created in disadvantaged areas of the world and limited contributions from local scholars and institutions, problematic. The open divide we observed in this research, that is, the disparity in academic contributions from across the globe, might indicate that local and bottom-up efforts to create open educational opportunities are either limited or they are not represented in the broader literature using English. These issues should be further explored in future studies.

Finally, the distribution of institutional affiliations showed that many of the universities which claim that they adopted open and/or distance education as a teaching and learning model have not significantly contributed to the research in the field. This raises questions as to the extent of their vision for adopting openness, whether they employ it only to attract more students and use it as a label/brand. In addition, as noted in the Findings and Discussion section of this paper, individual researchers can make significant contributions to the field and impact country profiles in terms of research output and outreach. Yet, it is not clear to what extent these individual efforts are recognised and promoted further by the wider open education community, which is an area that should be further explored. 
Based on the findings of the study, the following suggestions can be considered for the future of openness in education. First, in order to lessen the open divide between the global north and the south, there is a need to support and highlight local initiatives and contributions in the global south and adopt inclusive publishing practices and dissemination methods (e.g., publishing a resource in different languages and in different ways). Such measures would help raise awareness about openness and build collective knowledge. Second, there should be a stronger focus on open practice and culturally relevant pedagogy in all areas of open education. Third, new strategies and policies need to be developed to eliminate barriers in OERs and OEPs, which is crucial for fully benefiting from openness in education and reach wider populations. This issue is also important for sustainability and adoption of openness at different levels (e.g., individual, institutional or international). Finally, we call for a need to better extend openness to all areas of education, not just higher education, with a deeper focus on ethics and value.

The Cape Town Open Education Declaration (2007b) states: "Open education is a living idea. As the movement grows, this idea will continue to evolve" (para. 3). The trends observed in this study suggest that research on openness in education will continue to flourish and expand across different fields and disciplines. The critical issues raised in this study, particularly the open divide, should be addressed in future studies to make this idea even more ethical and inclusive.

\section{Acknowledgments}

This study was supported by Anadolu University Scientific Research Projects Commission under the grant no: $1705 \mathrm{E} 413$ and 1805E123.

\section{References}

Aboelela, S. W., Larson, E., Bakken, S., Carrasquillo, A. F., Formicola, A., Glied, S. A. ... Gebbie, K. M. (2007). Defining interdisciplinary research: Conclusions from a critical review of the literature. Health Services Research, 42(1), 329-346. https://doi.org/10.1111/j.1475-6773.2006.00621.x

Almendro, D., \& Silveira, I. F. (2018). Quality assurance for open educational resources: The OER trust framework. International Journal of Learning, Teaching and Educational Research, 17(3), 1-14. https://doi.org/10.26803/ijlter.17.3.1

Andrade, A., Ehlers, U., Caine, A., Carneiro, R., Conole, G., Kairamo, A. ... Holmberg, C. (2011). Beyond OER: Shifting focus from resources to practices. OPAL Report 2011. Lisbon, Essen. Retrieved from http://duepublico.uni-duisburg-essen.de/servlets/DerivateServlet/Derivate25907/OPALReport2011_Beyond_OER.pdf

Atkins, D. E., Brown, J. S., \& Hammond, A. L. (2007). A review of the open educational resources (OER) movement: Achievements, challenges, and new opportunities. Retrieved from https://hewlett.org/wp-content/uploads/2016/08/ReviewoftheOERMovement.pdf

Baker, F. W. (2017). An alternative approach: Openness in education over the last 100 years. TechTrends, 61(2), 130-140. https://doi.org/10.1007/s11528-016-0095-7

Banks, S. P., Louie, E., \& Einerson, M. (2000). Constructing personal identities in holiday letters. Journal of Personal and Social Relationships, 17(3), 299-327. Retrieved from http://journals.sagepub.com/doi/pdf/10.1177/0265407500173001

Bateman, P., Lane, A., \& Moon, R. (2012). An emerging typology for analysing OER initiatives. Proceedings of Cambridge 2012: Innovation and Impact - Openly Collaborating to Enhance Education, a joint meeting of OER12 and OpenCourseWare Consortium Global 2012 (pp. 19-28). Cambridge. Retrieved from http://oro.open.ac.uk/33243/

Beetham, H., Falconer, I., McGill, L., \& Littlejohn, A. (2012). Open practices: Briefing paper [JISC]. Retrieved from https://oersynth.pbworks.com/w/file/fetch/58444186/Open\%20Practices\%20briefing\%20paper.pdf

Bossu, C., Brown, M., \& Bull, D. (2012). Do open educational resources represent additional challenges or advantages to the current climate of change in the Australian higher education sector? Proceedings of the 29th Annual Conference of the Australasian Society for Computers in Learning in Tertiary Education (ASCILITE 2012) (pp. 124-132). Wellington. Retrieved from https://core.ac.uk/download/pdf/11050461.pdf

Bozkurt, A., Akgun-Ozbek, E., Onrat-Yilmazer, S., Erdogdu, E., Ucar, H., Guler, E. ... Aydin, C. H. (2015). Trends in distance education research: A content analysis of journals 2009-2013. International 
Review of Research in Open and Distributed Learning, 16(1), 330-363.

https://doi.org/10.19173/irrodl.v16i1.1953

Bozkurt, A., \& Koseoglu, S. (2018). Openness in education and digital scholarship: An interview with Bonnie Stewart. E-Learn Magazine, 2018(2). Retrieved from https://elearnmag.acm.org/archive.cfm?aid=3185174

Brown, J. S., \& Adler, R. P. (2008). Minds on fire: Open education, the long rail, and learning 2.0. Educause Review, 43(1), 16-32. Retrieved from https://er.educause.edu/ /media/files/articledownloads/erm0811.pdf

Camilleri, A. F., Ehlers, U. D., \& Pawlowski, J. (2014). State of the art review of quality issues related to open educational resources (OER). Luxembourg: Publications Office of the European Union. Retrieved from https://ec.europa.eu/jrc/en/publication/state-art-review-quality-issues-related-openeducational-resources-oer

Campbell, D. T., \& Fiske, D. W. (1959). Convergent and discriminant validation by the multitraitmultimethod matrix. Psychological Bulletin, 56(2), 81-105. http://psycnet.apa.org/doi/10.1037/h0046016

Coffey, J. (1977). Open learning opportunities for mature students. In C. Davies (Ed.), Open learning systems for mature students (CET Working Paper 14). London: Council for Educational Technology.

Coffey, J. (1988). The opening learning movement. Innovations in Education \& Training International, 25(3), 195-196.

Cronin, C. (2017). Openness and praxis: Exploring the use of open educational practices in higher education. The International Review of Research in Open and Distributed Learning, 18(5), 15-34. https://doi.org/10.19173/irrodl.v18i5.3096

Dalsgaard, C., \& Thestrup, K. (2015). Dimensions of openness: Beyond the course as an open format in online education. The International Review of Research in Open and Distributed Learning, 16(6), 7897. https://doi.org/10.19173/irrodl.v16i6.2146

Denzin, N. K. (1970). The research act: A theoretical introduction to sociological methods. Chicago, IL: Aldine.

Ehlers, U. D. (2011). Extending the territory: From open educational resources to open educational practices. Journal of Open Flexible and Distance Learning, 15(2), 1-10. Retrieved from http://www.jofdl.nz/index.php/JOFDL/article/view/64

Ehlers, U. D., \& Conole, G. (2010, May). Open educational practices: Unleashing the power of OER. Paper presented at UNESCO Workshop on OER, Namibia. Retrieved from

https://oerknowledgecloud.org/sites/oerknowledgecloud.org/files/OEP_Unleashing-the-power-ofOER.pdf

Geser, G. (Ed.) (2007). Open educational practices and resources: OLCOS roadmap 2012. Salzburg: Salzburg Research/EduMedia Group. Retrieved from http://www.olcos.org/cms/upload/docs/olcos_roadmap.pdf

Gough, D., Oliver, S., \& Thomas, J. (2012). An introduction to systematic reviews. London: Sage.

Hansen, D., Shneiderman, B., \& Smith, M. A. (2010). Analyzing social media networks with NodeXL: Insights from a connected world. Amsterdam: Morgan Kaufmann.

Havemann, L. (2016). Open educational resources. In M. A. Peters (Ed.), Encyclopedia of educational philosophy and theory (pp. 1-7). Singapore: Springer.

Hearst, M. (2003). What is text mining? Retrieved from http://people.ischool.berkeley.edu/ hearst/textmining.html

Hoy, W. K., \& Jalovick, J. M. (1979). Open education and pupil control ideologies of teachers. The Journal of Educational Research, 73(1), 45-49. https://doi.org/10.1080/00220671.1979.10885203

Jordan, K., \& Weller, M. (2017) Openness and education: A beginner's guide. Global OER Graduate Network. Retrieved from https://www.slideshare.net/GO-GN/openness-and-education-a-beginnersguide

Kanwar, A., Balasubramanian, K., \& Umar, A. (2010). Toward sustainable open education resources: A perspective from the global south. American Journal of Distance Education, 24(2), 65-80. https://doi.org/10.1080/08923641003696588

Kimchi, J., Polivka, B., \& Stevenson, J.S. (1991). Triangulation: Operational definitions. Nursing Research, 40(6), 364-366. Retrieved from https://journals.lww.com/nursingresearchonline/citation/1991/11000/triangulation_operational defini tions.9.aspx

Knox, J. (2013). The limitations of access alone: Moving towards open processes in education technology. Open Praxis, 5(1), 21-29. https://doi.org/10.5944/openpraxis.5.1.36 
Koseoglu, S., \& Bozkurt, A. (2018a). An exploratory literature review on open educational practices. Distance Education (in press).

Koseoglu, S., \& Bozkurt, A. (2018b, April). Research patterns and trends on open educational practices: An exploratory literature review. Paper presented at OER18: Open to All, the 9th Annual Conference for Open Education Research, Practice and Policy, Bristol. Retrieved from https://oer18.oerconf.org/sessions/research-patterns-and-trends-on-open-educational-practices-anexploratory-literature-review-1890/

Krippendorff, K. (1980). Content analysis: An introduction to its methodology. Newbury Park: Sage Publications.

Lane, A. (2011). Developing innovative systems for supportive open teaching practices in higher education. Journal for the Systemic Innovation of Education, 1(1), 32-46. Retrieved from http://oro.open.ac.uk/30279/

Laverde, A. C., \& Arias, M. H. (2015). Open production of an educational digital content: A case study. Opción, 31(4), 312-327. Retrieved from http://www.redalyc.org/html/310/31045569020/

Lessig, L. (2004). Free culture. New York, NY: The Penguin Press.

Lewis, R. (1986). What is open learning? Open Learning, 1(2), 5-10. https://doi.org/10.1080/0268051860010202

López, X., Valenzuela, J., Nussbaum, M., \& Tsai, C. C. (2015). Some recommendations for the reporting of quantitative studies. Computers \& Education, 91(C), 106-110. https://doi.org/10.1016/j.compedu.2015.09.010

McAndrew, P. (2010). Defining openness: updating the concept of" open" for a connected world. Journal of interactive Media in Education, 2010(2). Retrieved from https://jime.open.ac.uk/article/2010-10/

McGreal, R. (2017). Special report on the role of open educational resources in supporting the sustainable development goal 4: Quality education challenges and opportunities. The International Review of Research in Open and Distributed Learning, 18(7), 292-305. Retrieved from http://www.irrodl.org/index.php/irrodl/article/view/3541/4433

Mishra, S. (2012). Openness in education: Some reflections on MOOCs, OERs and ODL. Retrieved from http://oasis.col.org/handle/11599/1038?show=full

Moore, M. G., \& Kearsley, G. (2005). Distance education: A systems view. Canada: Wadsworth.

Mulder, F. (2015). Open(ing up) education for all ... Boosted by MOOCs? (Foreword). In C. J., Bonk, M. M. Lee, T. C. Reeves, \& T. H. Reynolds (Eds.). MOOCs and open education around the world (p. xvii-xxvii). New York, NY: Routledge.

Murphy, A. (2013). Open educational practices in higher education: Institutional adoption and challenges. Distance Education, 34(2), 201-217. https://doi.org/10.1080/01587919.2013.793641

Naidu, S. (2016). The case for open educational practice. Distance Education, 37(1), 1-3. https://doi.org/10.1080/01587919.2016.1157010

Nerantzi, C., \& Gossman, P. (2015). Towards collaboration as learning: Evaluation of an open CPD opportunity for HE teachers. Research in Learning Technology, 23. Retrieved from https://journal.alt.ac.uk/index.php/rlt/article/view/1661/pdf 6

Nielsen, L. (2011). Classifications of countries based on their level of development: How it is done and how it could be done. Retrieved from https://www.imf.org/en/Publications/WP/Issues/2016/12/31/Classifications-of-Countries-Basedontheir-Level-of-Development-How-it-is-Done-and-How-it-24628

Nissani, M. (1997). Ten cheers for interdisciplinarity: The case for interdisciplinary knowledge and research. The Social Science Journal, 34(2), 201-216. https://doi.org/10.1016/S0362-3319(97)90051-3

Pazurek, A., \& Feyissa, S. (2015). Digital divide. In J. M. Spector (Ed.). The SAGE encyclopedia of educational technology (p.204-205). Thousand Oaks, CA: Sage Publications.

Peter, S., \& Deimann, M. (2013). On the role of openness in education: A historical reconstruction. Open Praxis, 5(1), 7-14. https://doi.org/10.5944/openpraxis.5.1.23

Peters, M. A. (2008). The history and emergent paradigm of open education. In M. A. Peters, \& R. G. Britez (Eds.), Open education and education for openness (pp. 3-15). Rotterdam: Sense Publishers.

Peters, M. A., \& Britez, R. G. (2008). Introduction: Open education and education for openness. In M. A. Peters, \& R. G. Britez (Eds.), Open education and education for openness (pp. xvii-xxii). Rotterdam: Sense Publishers.

Petticrew, M., \& Roberts, H. (2008). Systematic reviews in the social sciences: A practical guide. Malden: John Wiley \& Sons.

Pomerantz, J., \& Peek, R. (2016). Fifty shades of open. First Monday, 21(5). Retrieved from http://firstmonday.org/article/view/6360/5460 
Poynder, R. (2018, January 2). Preface: Open divide? [Blog Post]. Retrieved from https://poynder.blogspot.co.uk/2018/01/preface-open-divide.html

Rolfe, V. (2017). Striving toward openness: But what do we really mean? The International Review of Research in Open and Distributed Learning, 18(7). 75-88. https://doi.org/10.19173/irrodl.v18i7.3207

Sabadie, J., Muñoz, J., Punie, Y., Redecker, C., \& Vuorikari, R. (2014). OER: A European policy perspective. Journal of Interactive Media in Education, 2014(1). http://doi.org/10.5334/2014-05

Scanlon, E., McAndrew, P., \& O'Shea, T. (2015). Designing for educational technology to enhance the experience of learners in distance education: how open educational resources, learning design and MOOCs are influencing learning. Journal of Interactive Media in Education, 2015(1), 1-9. https://doi.org/10.5334/jime.al

Scopus. (n.d.). About Scopus. Retrieved from https://www.elsevier.com/solutions/scopus

Siemens, G. (2013). Massive open online courses: Innovation in education. In R. McGreal, W. Kinuthia, \& S. Marshall (Eds), Open educational resources: Innovation, research and practice (pp. 5-16). Vancouver: Commonwealth of Learning, Athabasca University.

Smith, A. E., \& Humphreys, M. S. (2006). Evaluation of unsupervised semantic mapping of natural language with Leximancer concept mapping. Behavior Research Methods, 38(2), 262-279. Retrieved from https://link.springer.com/content/pdf/10.3758\%2FBF03192778.pdf

Smith, M. L., \& Seward, R. (2017). Openness as social praxis. First Monday, 22(4). Retrieved from https://firstmonday.org/ojs/index.php/fm/article/view/7073/6087

Stylianakis, G., Moumoutzis, N., Arapi, P., Mylonakis, M., \& Christodoulakis, S. (2014). COLearn and open discovery space portal alignment: A case of enriching open learning Infrastructures with collaborative learning capabilities. Proceedings of the 2014 International Conference on Interactive Mobile Communication Technologies and Learning, Thessalonika, 252-256. Retrieved from https://ieeexplore.ieee.org/document/7011142/

The Cape Town Open Education Declaration (2007a). Cape Town Open Education Declaration: Unlocking the promise of open educational resources. Retrieved from http://www.capetowndeclaration.org/read-the-declaration

The Cape Town Open Education Declaration (2007b). The Cape Town Open Education Declaration. Retrieved from http://www.capetowndeclaration.org/

The Commonwealth of Learning (2000). An introduction to open and distance learning. Retrieved from http://oasis.col.org/bitstream/handle/11599/138/ODLIntro.pdf?sequence=1\&isAllowed=y

Thille, C. (2008). Building open learning as a community-based research activity. In T. Iiyoshi, \& M. S. V. Kumar (Eds.), Opening up education: The collective advancement of education through open technology, open content, and open knowledge (pp. 165-179). Cambridge, MA: MIT Press.

UNESCO (2002). Forum on the impact of open courseware for higher education in developing countries: Final report. Retrieved from www.unesco.org/iiep/eng/focus/opensrc/PDF/OERForumFinalReport.pdf

UNESCO, \& Commonwealth of Learning (2011). Guidelines for open educational resources (OER) in higher education. Retrieved from http://unesdoc.unesco.org/images/0021/002136/213605e.pdf

Veletsianos, G., \& Shepherdson, P. (2015). Who studies MOOCs? Interdisciplinarity in MOOC research and its changes over time. The International Review of Research in Open and Distributed Learning, 16(3), 1-17. https://doi.org/10.19173/irrodl.v16i3.2202

Vest, C. M. (2006). Open content and the emerging global meta-university. Educause review, 41(3), 1830. Retrieved from https://er.educause.edu/ /media/files/article-downloads/erm0630.pdf

Weller, M. (2014). The battle for open: How openness won and why it doesn't feel like victory. London: Ubiquity Press.

Weller, M., Jordan, K., DeVries, I., \& Rolfe, V. (2018). Mapping the open education landscape: Citation network analysis of historical open and distance education research. Open Praxis, 10(2), 109-126. https://doi.org/10.5944/openpraxis.10.2.822

Wiley, D., Bliss, T. J., \& McEwen, M. (2014). Open educational resources: A review of the literature. In Handbook of research on educational communications and technology (pp. 781-789). New York, NY: Springer.

Yuan, L., MacNeill, S., \& Kraan, W. G. (2008). Open educational resources-opportunities and challenges for higher education. Retrieved from https://oerknowledgecloud.org/sites/oerknowledgecloud.org/files/OER_Briefing_Paper.pdf

Zancanaro, A., Todesco, J., \& Ramos, F. (2015). A bibliometric mapping of open educational resources. The International Review of Research in Open and Distributed Learning, 16(1), 1-23. https://doi.org/10.19173/irrodl.v16i1.1960 
Zawacki-Richter, O., \& Naidu, S. (2016). Mapping research trends from 35 years of publications in distance education. Distance Education, 37(3), 245-269.

https://doi.org/10.1080/01587919.2016.1185079

Zawacki-Richter, O., Alturki, U., \& Aldraiweesh, A. (2017). Review and content analysis of the International Review of Research in Open and Distance/Distributed Learning (2000-2015). The International Review of Research in Open and Distributed Learning, 18(2), 1-26. https://doi.org/10.19173/irrodl.v18i2.2806

Corresponding author: Aras Bozkurt, arasbozkurt@,anadolu.edu.tr

Australasian Journal of Educational Technology (C) 2019.

Please cite as: Bozkurt, A., Koseoglu, S., \& Singh, L. (2019). An analysis of peer reviewed publications on openness in education in half a century: Trends and patterns in the open hemisphere. Australasian Journal of Educational Technology, 35(4), 78-97. https://doi.org/10.14742/ajet.4252 
Appendix A

50 shades of income inequality

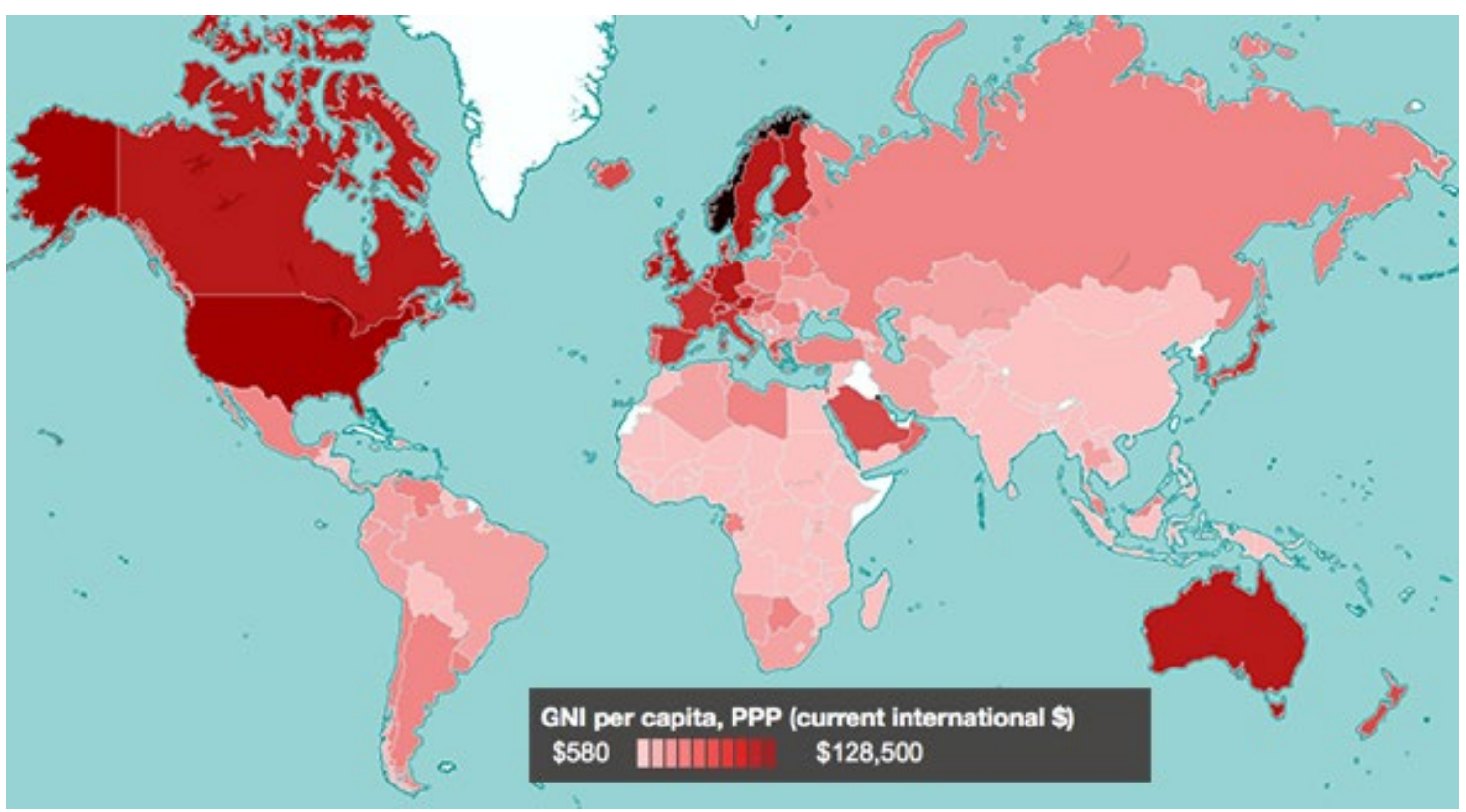

The map shows the Gross National Income (GNI) of countries in 2011. Dark shades indicate high income compared to rest. Retrieved from http://www.nationsonline.org/oneworld/GNI_PPP_of countries.htm 


\section{Appendix B}

Sociogram based on social network analysis of the keywords in the sampled publications

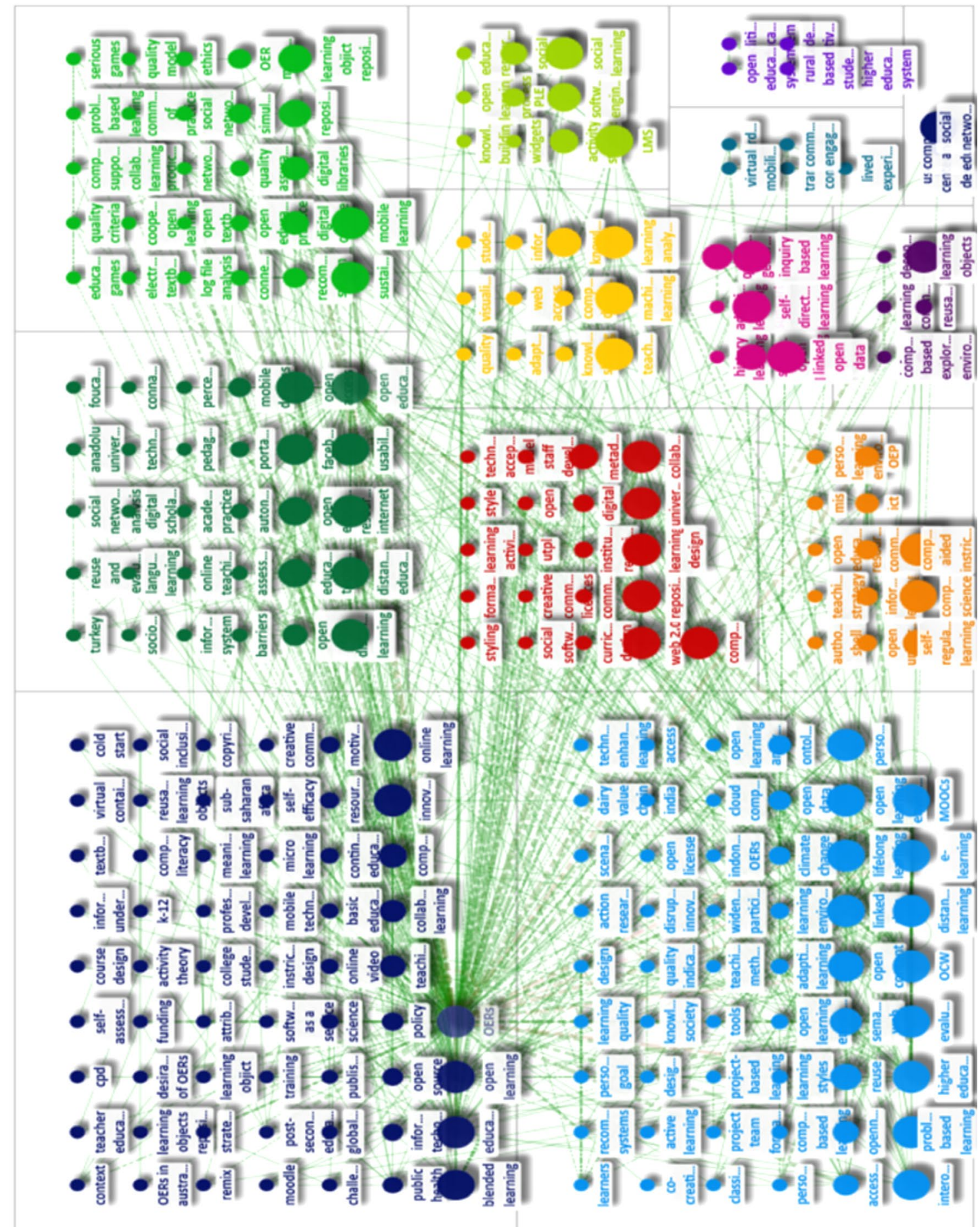

